\title{
Bacteriological profiles of Blood culture isolates by BacT/ALERT 3D automated system
}

\author{
ABMA Wadud $^{1}$, Ml Khalil², AKM Shamsuzzaman ${ }^{3}, \mathrm{Kms} \mathrm{Islam}^{4}$, BB Mondal ${ }^{5}$, MZ Banda ${ }^{6}$, MSK Shahid Ullah ${ }^{7}$
}

\begin{abstract}
:
Automated sensor based blood culture system is superior to traditional two steps or biphasic methods regarding time of isolation and avoiding contamination. The present study documented various aspects of blood culture isolates done in a well set automated system (BacT/ALERT 3D, BIOMERIUX, USA) at Dhaka city. As per monthly distribution of samples, number of samples showed increased trend from March and declining trend in November with peak in July, August, September and October. Average detection time was found as 20 hours. Among the bacterial pathogens isolated, Salmonella typhi was the most common (66.62\%) followed by Salmonella paratyphi (S. paratyphi A \& B 22.21\%). Antibiotic susceptibility patterns (\%) of the isolated organisms are shown in Table - VI. The results are not much divergent in respect of particular pathogens. The mostly focused results of common blood culture pathogen Salmonella typhi and Salmonella paratyphi show sensitivity pattern of over 95\% towards Amoxyclav (98.0\% \& 99.36\%), Aztreonam, Amikacin, Cefaclor, Cefixim, Cettazidime, Ceftriaxone, Cephalexine and Ciprofloxacin. Almost all the strains were found resistant towards Azithromycin. No satisfactory sensitivity was obtained towards Cotrimoxazole, Gentamicin, Mecillinam and Nalidixic acid. Gram negative bacteria including Escherichia coli as blood culture isolates were resistant towards used panel of antibiotics except Ciprofloxacin, Cotrimoxazole, Gentamicin and Mecillinam. Over 90\% strains showed resistant towards Amoxycillin and Azithromycin. The study established that blood culture reports with positive growth and antimicrobial susceptibility can be generated within maximum of 72 hours by automated culture system.
\end{abstract}

Key words: Automated blood culture, bacterial pattern, antimicrobial susceptibility.

\section{Introduction}

Diagnosis of infectious diseases is concerned with the isolation and identification of aetiological agents. Blood culture is the single most important procedure to detect systemic infection due to bacteria.In the procedure, there is ample chance of contamination occurring at some point. This culture results depend largely on the quality of the specimen, the timing and the care, with which it is collected, and the technical effificiency and experience of laboratory personnel.Bacteraemia is often life-threatening and Blood culture can providebacteriological diagnosis as fatal condition that necessitates immediate treatment.

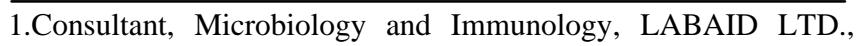
Dhaka

2.Microbiologist, Popular Pharmaceuticals Ltd., Dhaka

3.Associate Professor of Microbiology, Shaheed Suhrawardy Medical College, Dhaka

4.Professor, Department of Microbiology, Shaheed Suhrawardy Medical College, Dhaka

5.Coordinator, LABAID Diagnostics

6.Lab Manager, LABAID Diagnostics

7.Assistant Professor .Department of Microbiology ,NICVD,Dhaka

Corresponding author:

Dr. AB M Abdul Wadud

Consultant, Microbiology \& Immunology, LABAID GROUP, Dhaka

Email: drwadud@labaidgroup. well as selection of appropriate of antibiotic. Since bacteraemia frequently portends life- threatening comillness, its early detection is essential. Blood culture provides valuable information for the management of febrile, acutely ill patients with or without localizing symptoms and signs. In addition to its diagnostic significance, recovery of an infectious agent from the blood provides invaluable aid in determining antimicrobial therapy. Every effort should therefore be made to isolate the causative organisms in bacteraemia. Although, negative result of blood culture suggests that the patient was not bacteraemic at the time the specimen was taken, but there might be inappropriateness of the procedure. Blood cultures are rarely positive in an otherwise healthy adult.

Ideally contamination rates should not exceed $3 \%{ }^{1}$. Traditional procedures using two steps methods, i.e. primary isolation in broth followed by subsequent identification and antimicrobial susceptibility needs a long time. Not only long time, there is a high chance of contamination due to technical reluctance. Considering all those factors, automated system is undoubtedly superior method. Documentation of the performance of automated blood culture system is important to inform particularly the concerned physicians and specialists. This study was done as an attempt to provide updated information of BacT/ALERT culture system adopted by a well known private laboratory at Dhaka city. 


\section{Materials and Methods}

During the period from April 2007 to March 2008, 4915 blood samples from adult and children (below 12 years) were subjected to automated blood culture system at LABAID LTD, Dhaka. All samples were collected in BacT/ALERT®FA and BacT/ ALERT®PF bottle (BIOMERIEUX, USA) irrespective of antibiotics administration. Quantity of blood sample from adult and children was $5-10 \mathrm{ml}$ and 1-5 ml respectively collected with all aseptic precautions described in the manual of the manufacturer. Samples were incubated in the automated BacT/ALERT 3D system (BIOMERIEUX, USA) for 72 hours. According to manufacturer's instructions, any sample that did not generate any signal within 72 hours of incubation was interpreted as no growth (negative).

The preliminary signal of bacterial growth in BacT/ALERT bottle was detected and displayed on the 3D monitor of BacT/ALERT system mentioning the detection time. Specific identification of all culture positive samples was accomplished by sub-culture on Blood agar, Chocolate agar and MacConkeys agar media (OXOID CO. UK). Inoculated Blood agar and MacConkeys agar plates were incubated aerobically at 370 C. The Chocolate agar plates were incubated at 370 C under $5-10 \%$ CO2 condition (Candle jar) and examined after 18-24 hours of incubation. Gram's stain, battery of biochemical and serological test were done for final identification2.

Antimicrobial susceptibility test was carried out by the Kirby-Bauer disc diffusion method using Muller Hinton agar media and antibiotic disc from OXOID CO. UK. Standard panel of antibiotic discs were tested for each organism3. For quality control, ATCC strains of Staphylococcus aureus (ATCC 25923) and Escherichia coli (ATCC 25922) were used side by side. The results of susceptibility test were classified into sensitive (S), intermediate (I) and resistant (R). The isolates with intermediate susceptibility were included in resistant categories.

\section{Results}

Table-l shows the adult and children wise distribution of 4915 blood culture samples with the values as 2938 (59.78 \%) and 1977 (40.22\%) respectively. Table II shows the results of culture. Out of 4915 sample, 707 (14.38\%) were positive, 341 (6.94\%) were falsepositive and 3, 867 (78.68 \%) were negative. Among 707 positive samples 449 (63.51\%) were adult and
Table - I: Distribution of children and adult specimens

\begin{tabular}{|lll|}
\hline Age & Number & Percentage (\%) \\
\hline Adult & 2938 & 59.78 \\
\hline Children* & 1977 & 40.22 \\
\hline Total & 4,915 & 100 \\
\hline
\end{tabular}

* Age below 12 years.

Table-II: Rate of culture positive, false-positive and negative samples

\begin{tabular}{|lll|}
\hline Results of culture) & Number & Percentage (\%) \\
\hline $\begin{array}{l}\text { Growth of bacteria } 707 \\
\text { (Positive) }\end{array}$ & 14.36 \\
\hline False positive & 341 & 06.96 \\
\hline $\begin{array}{l}\text { No } \\
\text { (Negative) }\end{array}$ & growth 3.867 & 78.68 \\
\hline Total & 4.915 & 100 \\
\hline
\end{tabular}

Table-III: Distribution of the positive specimen among children and adult $(\mathrm{n}=707)$

\begin{tabular}{|lll|}
\hline Adult/Child & Number & Percentage (\%) \\
\hline Adult & 449 & 63.51 \\
\hline Children* & 258 & 36.49 \\
\hline Total & 707 & 100 \\
\hline
\end{tabular}

Table - IV: Distribution of isolated bacterial pathogens. $(\mathrm{n}=707)$

\begin{tabular}{|lll|}
\hline Bacteria & Number & Percentages (\%) \\
\hline Salmonella typhi & 471 & 66.62 \\
\hline Salmonella paratyphi & A 157 & 22.21 \\
\hline Escherichia coli & 43 & 06.08 \\
\hline Pseudomonas spp. & 15 & 02.12 \\
\hline Acinetobacter spp. & 07 & 00.99 \\
\hline Klebsiella spp. & 03 & 00.42 \\
\hline Staph aureus & 02 & 00.28 \\
\hline Proteus spp. & 01 & 00.14 \\
\hline Gram negative bacilli & 08 & 01.14 \\
\hline Total & 707 & 100 \\
\hline
\end{tabular}


Table V: Antibiotic susceptibility patterns (\%) of the isolated organisms

\begin{tabular}{|c|c|c|c|c|c|c|c|c|c|}
\hline 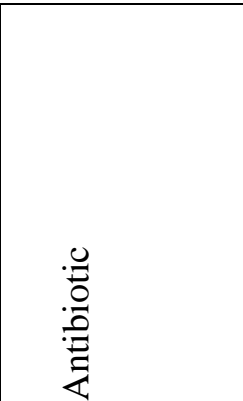 & 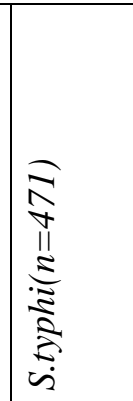 & 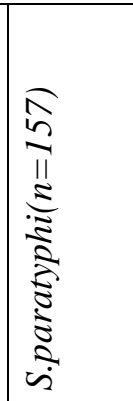 & 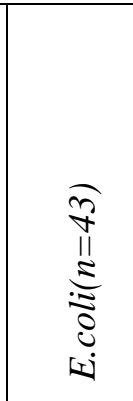 & 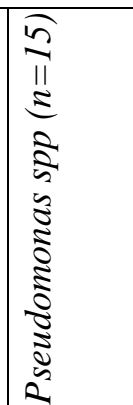 & 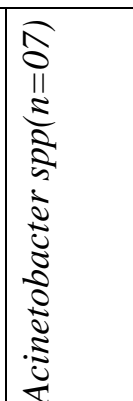 & 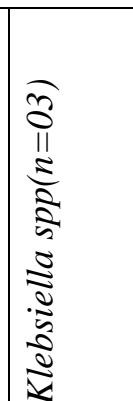 & 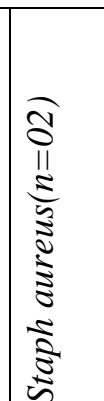 & 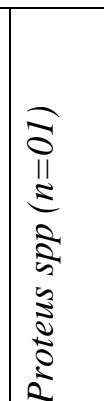 & 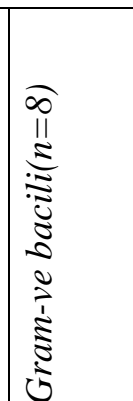 \\
\hline Amoxycillin & \begin{tabular}{|l|}
292 \\
$(62.00)$
\end{tabular} & $\begin{array}{l}110 \\
(70.00)\end{array}$ & $\begin{array}{l}4 \\
(9.30)\end{array}$ & $\begin{array}{l}4 \\
(9.30)\end{array}$ & 0 & 0 & 0 & 0 & 0 \\
\hline Amoxyclav & $\begin{array}{l}464 \\
(98.5)\end{array}$ & $\begin{array}{l}156 \\
(99.36)\end{array}$ & $\begin{array}{l}20 \\
(46.5)\end{array}$ & $\begin{array}{l}20 \\
(46.5)\end{array}$ & 0 & 0 & $\begin{array}{l}2 \\
(100)\end{array}$ & 0 & $\begin{array}{l}3 \\
(37.50)\end{array}$ \\
\hline Azithromycin & $\begin{array}{l}02 \\
(0.42)\end{array}$ & 0 & $\begin{array}{l}3 \\
(6.98)\end{array}$ & $\begin{array}{l}3 \\
(6.98)\end{array}$ & 0 & $\begin{array}{l}1 \\
(33.33)\end{array}$ & $\begin{array}{l}1 \\
(50)\end{array}$ & 0 & $\begin{array}{l}5 \\
(62.50)\end{array}$ \\
\hline Aztreonam & $\begin{array}{l}461 \\
(97.88)\end{array}$ & $\begin{array}{l}149 \\
(94.90)\end{array}$ & $\begin{array}{l}20 \\
(46.51)\end{array}$ & $\begin{array}{l}20 \\
(46.51)\end{array}$ & $\begin{array}{l}2 \\
(28.57)\end{array}$ & $\begin{array}{l}0 \\
2\end{array}$ & NT & 0 & $\begin{array}{l}7 \\
(87.50)\end{array}$ \\
\hline Amikacin & $\begin{array}{l}452 \\
(95.97)\end{array}$ & $\begin{array}{l}152 \\
(96.82)\end{array}$ & $\begin{array}{l}25 \\
(58.14)\end{array}$ & $\begin{array}{l}25 \\
(58.14)\end{array}$ & $\begin{array}{l}1 \\
(14.29)\end{array}$ & (66.67) & $\begin{array}{l}2 \\
(100)\end{array}$ & $\begin{array}{l}1 \\
(100)\end{array}$ & $\begin{array}{l}4 \\
(50.00)\end{array}$ \\
\hline Cefaclor & $\begin{array}{l}463 \\
(99.58)\end{array}$ & $\begin{array}{l}148 \\
(94.27)\end{array}$ & $\begin{array}{l}14 \\
(32.56)\end{array}$ & $\begin{array}{l}14 \\
(32.56)\end{array}$ & 0 & 0 & $\begin{array}{l}2 \\
(100)\end{array}$ & 0 & $\begin{array}{l}2 \\
(25.00)\end{array}$ \\
\hline Cefixime & $\begin{array}{l}466 \\
(98.94)\end{array}$ & $\begin{array}{l}153 \\
(97.45)\end{array}$ & $\begin{array}{l}16 \\
(37.21)\end{array}$ & $\begin{array}{l}16 \\
(37.21)\end{array}$ & $\begin{array}{l}1 \\
(14.29)\end{array}$ & 0 & $\begin{array}{l}2 \\
(100)\end{array}$ & 0 & $\begin{array}{l}5 \\
(62.50)\end{array}$ \\
\hline Ceftazidime & $\begin{array}{l}460 \\
(97.66)\end{array}$ & $\begin{array}{l}156 \\
(99.36)\end{array}$ & $\begin{array}{l}21 \\
(48.84)\end{array}$ & $\begin{array}{l}21 \\
(48.84)\end{array}$ & $\begin{array}{l}1 \\
(14.29)\end{array}$ & 0 & $\begin{array}{l}1 \\
(50)\end{array}$ & 0 & $\begin{array}{l}5 \\
(62.50)\end{array}$ \\
\hline Ceftriaxone & $\begin{array}{l}470 \\
(99.79)\end{array}$ & $\begin{array}{l}156 \\
(99.36)\end{array}$ & $\begin{array}{l}19 \\
(44.19)\end{array}$ & $\begin{array}{l}19 \\
(44.19)\end{array}$ & $\begin{array}{l}1 \\
(14.29)\end{array}$ & 0 & $\begin{array}{l}1 \\
(50)\end{array}$ & $\begin{array}{l}1 \\
(100)\end{array}$ & $\begin{array}{l}6 \\
(75)\end{array}$ \\
\hline Cephalexin & $\begin{array}{l}459 \\
(97.45)\end{array}$ & $\begin{array}{l}135 \\
(85.99)\end{array}$ & $\begin{array}{l}10 \\
(23.26)\end{array}$ & $\begin{array}{l}10 \\
(23.26)\end{array}$ & $\begin{array}{l}1 \\
(14.29)\end{array}$ & 0 & 0 & 0 & $\begin{array}{l}1 \\
(12.50)\end{array}$ \\
\hline Ciprofloxacin & $\begin{array}{l}440 \\
(93.42)\end{array}$ & $\begin{array}{l}144 \\
(91.72)\end{array}$ & $\begin{array}{l}24 \\
(55.81)\end{array}$ & $\begin{array}{l}24 \\
(55.81)\end{array}$ & $\begin{array}{l}2 \\
(28.57)\end{array}$ & 0 & $\begin{array}{l}1 \\
(50)\end{array}$ & 0 & $\begin{array}{l}7 \\
(87.50)\end{array}$ \\
\hline Cotrimoxazole & $\begin{array}{l}245 \\
(52.02)\end{array}$ & $\begin{array}{l}138 \\
87.9\end{array}$ & $\begin{array}{l}25 \\
(58.14)\end{array}$ & $\begin{array}{l}25 \\
(58.14)\end{array}$ & $\begin{array}{l}2 \\
(28.57)\end{array}$ & $\begin{array}{l}1 \\
(33.33)\end{array}$ & $\begin{array}{l}1 \\
(50)\end{array}$ & 0 & $\begin{array}{l}5 \\
(62.50)\end{array}$ \\
\hline Gentamicin & $\begin{array}{l}456 \\
(96.82)\end{array}$ & $\begin{array}{l}152 \\
(96.82)\end{array}$ & $\begin{array}{l}25 \\
(58.14)\end{array}$ & $\begin{array}{l}25 \\
(58.14)\end{array}$ & 0 & $\begin{array}{l}2 \\
(66.67)\end{array}$ & $\begin{array}{l}1 \\
(50)\end{array}$ & $\begin{array}{l}1 \\
(100)\end{array}$ & $\begin{array}{l}2 \\
(25)\end{array}$ \\
\hline Mecillinam & $\begin{array}{l}420 \\
(89.17)\end{array}$ & $\begin{array}{l}149 \\
(94.90)\end{array}$ & $\begin{array}{l}34 \\
(79.06)\end{array}$ & $\begin{array}{l}34 \\
(79.06)\end{array}$ & 0 & $\begin{array}{l}1 \\
(33.33)\end{array}$ & NT & 0 & $\begin{array}{l}2 \\
(25)\end{array}$ \\
\hline Nalidixic Acid & $\begin{array}{l}25 \\
(5.31)\end{array}$ & $\begin{array}{l}3 \\
(1.9)\end{array}$ & $\begin{array}{l}11 \\
(25.58)\end{array}$ & $\begin{array}{l}11 \\
(25.58)\end{array}$ & 0 & 0 & 0 & 0 & $\begin{array}{l}3 \\
(37.5)\end{array}$ \\
\hline
\end{tabular}


58 (36.49\%) were children (Table-Ill)

Average, lowest and highest detection time of bacterial growth was 20 hours, 07 hours and 54 hours respectively. Over $99 \%$ positive and false-positive samples gave signal within 50 hours and no isolates were obtained beyond day 3 of incubation.

The monthly distribution \& number of samples showed increased trend from March and declining trend from November with peak in July, August, September and October. (Table-IV)

Among the bacterial pathogens isolated, Salmonella typhi was the most common (66.62\%) followed by Salmonella paratyphi (S. paratyphi A \& B 22.21\%), Escherechia coli, Pseudomonas spp., Acinetobacter spp, Klebsiella spp, Staph aureus, and Proteus spp. About 01.14(\%) isolates were identified as Gram negative bacilli. Most common contaminant was Staph. epidermidis. No fungal pathogen was isolated during this period (Table-V).

Antibiotic susceptibility patterns (\%) of the isolated organisms are shown in Table - VI. The results are not much divergent in respect of particular pathogens. The mostly focused results of common blood culture pathogen Salmonella typhi and Salmonella paratyphi show a sensitivity of over 95\% towards Amoxyclav (98.0\% \& 99.36\%), Aztreonam, Amikacin, Cefaclor, Cefixim, Ceftazidime, Ceftriaxone, Cephalexine and Ciprofloxacin. Almost all the strains were found resistant towards Azithromycin. No satisfactory sensitivity was obtained towards Cotrimoxazole, Gentamicin, Mecillinam and Nalidixic acid. Observed sensitivity results to Amoxycillin, Amoxyclav, Aztreonam, Amikacin, Cefaclor, Cefixim, Ceftazidime, Ceftriaxone, Cephalexin,

Ciprofloxacin, Cotrimoxazole, Gentamicin, Mecillinam and Nalidixic acid were $62.00 \%, 98.00 \%$, 00.42\%, 97.88\%, 95.97\%, 99.58\%, 98.94\%, 97.66\%, 99.79\%, 97.45\%, 93.42\%, 52.02\%, 96.82\%, 89.17\% \& 05.31\% respectively. Regarding Salmonella paratyphi observed values as sensitive to Amoxycillin, Amoxyclav, Aztreonam,Amikacin Cefaclor, Cefixim, Ceftazidime, Ceftriaxone, Cephalexine, Ciprofloxacin, Cotrimoxazole, Gentamicin, Mecillinam and Nalidixic acid 70.00\%, 99.36\% , 94.90\%, 96.82\%, 94.27\%, 97.45\%, 99.36\%, 99.36\%, 85.99\%, 91.72, 87.90\%, 96.82\%, 94.90\% \& 01.90\% respectively. All strain of Salmonella paratyphi was resistant to Azithromycin.

Over 50 \% strains of Escherichia coli as blood culture isolates were resistant towards used panel of antibiotics except Ciprofloxacin, Cotrimoxazole,
Gentamicin and Mecillinam. Over 90\% strains showed resistant towards Amoxycillin and Azithromycin. (Obtained values of sensitivity to Amoxycillin, Amoxyclav, Azithromycin, Aztreonam, Amikacin Cefaclor, Cefixim, Ceftazidime, Ceftriaxone, Cephalexine, Ciprofloxacin, Cotrimoxazole, Gentamicin, Mecillinam and Nalidixic acid 09.30\%, 46.50\%, 06.98\%, $46.51 \%$, 58.14\%, 32.56\%, 37.21\%, 48.84\%, 44.19\%, 23.26\%, 55.81\%, 58.14\%, 58.14\%, 79.06 \& 25.58\% respectively)

\section{Discussion}

Blood culture is a well-established procedure of the standard diagnostic workup for many infectious diseases. In the countries like Bangladesh, where all kinds of drugs including the antibiotics, are sold over the counter, misuse of antibiotics has been found to be responsible for developing pool of resistant bacteria as well as negative results of blood culture ${ }^{4}$. In that situation, advanced method like automated culture system might be an answer to resolve the problem. The present study was conducted to explore that probability.

The present study receded overall recovery rate of bacteria from blood culture as $14.38 \%$. One home study with similar design done in BSMMU found bacterial isolation rate as $09.88 \%{ }^{5}$. In other study from Bangladesh, recovery rate of bacterial pathogens from blood was $11.6 \%{ }^{6}$. Slightly higher isolation rate (20\%) was reported from study done in $\mathrm{Nepal}^{7}$. Findings of those studies were in good agreement with the result of the present study. But, higher isolation rate of bacteria from blood culture was reported from different studies done in other countries. A one-year study (August 1998-July 1999) of bacteraemia in febrile children was carried out in the Medical Unit III of Yangon Children's Hospital at Myanmar, where bacterial isolation rate was found as $54.2 \%{ }^{8}$. Another study over children in New Delhi reported the positivity of blood culture as $42 \%{ }^{9}$. Similar study in Japan found blood culture positive in paediatric samples as $53.6 \%{ }^{10}$. The present study found higher culture positive rate in adult samples (63.51\%) that did not correlate with studies described above. The reasons behind this outcome might be the selection criteria of samples. We included all samples came to the study laboratory irrespective of age and clinical conditions. But studies, with which we compared our result, were done on selective population at selective locations. Anyhow, empirical use of broad-spectrum antibiotics before collection of blood culture samples could not be ruled out. In the present study, most of the positive cultures were obtained after 24 hours of incubation (average 50 hours) and no isolates were obtained beyond day 3 of incubation. The maximum incubation time of 3 days would appear 
adequate to declare one sample as negative. The explanation behind such observation was well supported by the outcome of a study in USA, where blood cultures had been routinely incubated for 4 days instead of the 5 days recommended by the manufacturer. On day 5, numerous contaminations were detected. That event led them to adopt the policy of incubating blood culture for a maximum period of 4 days ${ }^{11}$.

The present study found Salmonella spp (88.83 \%) as most common isolates. This finding was in accordance with other studies at home or abroad. One study in Columbia reported Salmonella typhi recovery rate as $36.6 \%{ }^{12}$. In a study at Dhaka, Salmonella typhi was the single most common pathogen (72.7\%) among the recovered isolates6. Study at BSMMU, Dhaka, reported Salmonella typhi and Salmonella paratyphi isolation rate as $77.97 \%$ and $22.02 \%$ respectively ${ }^{5}$. Higher isolation rate of Salmonella species (causative agent of enteric fever) is a significant finding so far clinical impression is concerned. Because enteric fever is prevalent in Dhaka city due to improper sanitation system leading to gross faecal contamination of consumable water. Patients of enteric fever commonly attend their physicians as outpatient basis in the private chamber, from where they are sent to private laboratory for diagnostic tests. As a result, majority of febrile patients came with an indication of blood culture. Higher isolation is generally expected, but empirical use of antibiotic hinders the process. Having points in favor of the above explanation, the present study also observed higher count of blood culture samples as well as isolation rate of Salmonella typhi during summer and monsoon when weather remain hot and humid and water crisis is also seen ${ }^{6}$. In this study, rate of isolation of other pathogens was as follows: Escherechia coli 06.08 (\%), Pseudomonas spp 02.12 (\%), Gram-negative bacilli 01.14(\%), Acinetobacter spp 00.99 (\%), Klebsiella spp 00.42 (\%), Staph aureus $00.28(\%)$ and Proteus spp 00.14 (\%). Dissimilar observation was made in a study at Myanmar, where following Salmonella typhi (43.1\%), other bacteria included Escherichia coli (12.3\%), Staphylococcus aureus $(7.7 \%)$, Pseudomonas aeruginosa $(7.7 \%)^{8}$. In our study, isolation of other bacteria was lower than Myanmar study. The reason behind this fact is again the selective samples from randomly attending patients.

In this study, Salmonelle typhi shows very good sensitivity to commonly used and locally available antibiotics. Exceptionally, Azithromycin and Nalidixic acid showed low sensitivity (00.42\% and $05.31 \%$ ). One study in BSMMU recorded Azithromycin and
Nalidixic acid sensitivity as $81.80 \%$ and $13.5 \%$ respectively5. In case of Azithrimycin our finding disagree with BSMMU study. Very high use of Azithromycin might be the cause of acquiring resistance gene from environment that has resulted dramatic increase of phenotypic resistance. But, it requires further study to find out the real picture about Azithromycin resistance. Isolates other than Salmonella species (Escherechia coli, Klebsiella spp, Pseudomonas spp, Acinetobacter spp) showed considerable degree of resistance towards commonly used antibiotics (sensitivity range from $06.67 \%$ to $79.06 \%$ ). This observation well correlates with prevailing clinical situation. This fact might be due to development of ESBL among the Gram-negative bacilli. Further study can be done to explore this phenomenon.

In our study, all the Staph aureus were vancomycin sensitive, whereas $50 \%$ were methicillin resistant (MRSA). One study in Dhaka MRSAwere $70 \%{ }^{13}$. This study would help the physicians to make judicious choice of antibiotics and would be helpful for formulation of an antibiotic policy and antibiotic recycling for the treatment of deadly infectious diseases.

\section{Reference}

1. Weinbaum FIL, Danek S, Sixsmith M, et al. Doing it right the first time: quality improvement and the contaminant blood culture. J Clin Microbiol. 1997; 35:563-5.

2. Collee JG, Miles RS, Watt B. Tests for the identification of bacteria. In: Mackie and McCartney practical medical microbiology, 14 th ed. Collee JG, Fraser AG, Marmion BP, Simmons A, editors. Churchill Livingstone: London; 1996. p. 131-49.

3. Bauer AW, Kirby WM, Sherris JC, Turck M. Antibiotic susceptibility testing by a standardized single disk method. Am J Clin Pathol 1966; 45: 493-6.

4. Burke JP; Interscience Conference on Antimicrobial Agents and Chemotherapy Abstr Intersci Conf Antimicrob Agents Chemother Intersci Conf Antimicrob Agents Chemother. 1999 Sep 26-29; 39: 755 (abstract no. 623). bsiteat: http://gat.eway. nlm.nih.gov/MeetingAbstracts/ma?f= 1022459 61.html [accessed on 25 January 2009)

5.Saleh AA, SattarANI, Ahmed S and Miah MRA. Antibiotic sensitivity pattern of Salmonell species isolated by blood culture in Bangabandhu Sheikh Mujib Medical University, Dhaka. BJMM 2008 Jul; 2(2); 22-36.

6.Saha SK, Baqui AH, Hanif M, Darmstadt GL, Ruhulamin M, Nagatake T, et al. Typhoid fever in Bangladesh: implications for vaccination policy. Pediatric Infectious Disease Journal 2001 May; 20(5):521-524.

7.Shrestha P, Das BK, Bhatta NK, Jha DK, Das B, Setia A, et al. Clinical and Bacteriological Profiles of Blood Culture Positive Sepsis in Newborns. J. Nepal Paediatr.Soc 2008; 27(2): 64-67.

8. Than Nu Shwe, Mar Mar Nyein, Wut Yi and Aung Mon. Blood culture isolates from children admitted to Medical Unit III, Yangon Children's Hospital. 1998. Southeast Asian J Trap Med Public Health 2002 Dec; 33(4): 764-771. 
9. Ghanshyam D. Kumhar, V.G. Ramachandran and Piyush Gupta. Bacteriological Analysis of Blood Culture Isolates from Neonates in a Tertiary Care Hospital in India. J Health Popul Nutr 2002 Dec: 20(4): 343-347.

10. Niimi Yoshihiro, Saito Takako and Izumo Taeko. Isolation of microorganisms from blood cultures during 8 years at Sakai Municipal Hospital Frequency of isolation, number of samples per Bacteriological profiles of Blood culture isolates by BacT/ALERT 3D automated system case, and CVC-related bacteremla Sakai Municipal Hospital Medical Journal 2004; 7: 64-71

11. Doern GV, Brueggemann AB, Dunne WM, Jenkins SG, Halstead DC.McLaughlin JC. Four-day incubation period for blood culture bottles processed with the Difco ESP blood culture system. J Clin Microbiol 1997; 35:1290-2.

12. Marcela Mari'a Gaviria- Ruzi and Nora Mari'a Cardona-
Castro. Evaluation and Comparison of Different Blood Culture Techniques for Bacteriological Isolation of Salmonella typhi and Brucella abortus. J Clin Microbiol 1995 April; 33(4): 868-871.

13. Rahman MM, Huq JA, Morshed MAHG and Huq F. Antibiotic susceptibility Pattern of bacteria isolated from an urban referral hospital in Dhaka city. BJMM 2008; 02(02):7-11. 